\title{
Effects of Flag Leaf and Number of Vegetative Ramets on Sexual Reproductive Performance in the Clonal Grass Leymus chinensis
}

\author{
Jian Guo', Haiyan Li"*, Chan Zhou'² and Yunfei Yang ${ }^{1 *}$ \\ ${ }^{1}$ Key Laboratory of Vegetation Ecology, Ministry of Education, Institute of Grassland Science, Northeast Normal University, \\ Changchun, China, ${ }^{2}$ School of Life Sciences, Liaoning University, Shenyang, China
}

OPEN ACCESS

Edited by:

Chunhua Liu,

Wuhan University, China

Reviewed by:

Fei-Hai Yu,

Taizhou University, China

Wen-Hua You,

Jiangsu University, China

*Correspondence:

Haiyan L

lihy697@nenu.edu.cn

Yunfei Yang

yangyf@nenu.edu.cn

Specialty section:

This article was submitted to

Functional Plant Ecology,

a section of the journal

Frontiers in Plant Science

Received: 12 February 2020

Accepted: 12 October 2020

Published: 30 October 2020

Citation:

Guo J, Li H, Zhou C and Yang Y

(2020) Effects of Flag Leaf

and Number of Vegetative Ramets on

Sexual Reproductive Performance

in the Clonal Grass Leymus chinensis.

Front. Plant Sci. 11:534278.

doi: 10.3389/fp/s.2020.534278
Sexual reproduction is vital for population adaptation in clonal plants. The flag leaf is considered to be the primary contributor to sexual reproduction in cereal crops, and there is no unified conclusion on the effect of the number of vegetative ramets on grain yield. However, what effects of the flag leaf and the number of vegetative ramets on sexual reproductive performance of clonal grasses are largely unknown. To test this, under field natural conditions, we grew the rhizomatous grass Leymus chinensis in a homogeneous environment and conducted studies concerning the growth, reproduction and physiology of reproductive ramets in clonal populations. We measured the growth characteristics of different aged leaves, dynamically measured the net photosynthetic rate of different aged leaves and organ biomass, measured the sexual reproductive characteristics of reproductive ramets that had different numbers of connecting vegetative ramets, and performed isotope $\left({ }^{15} \mathrm{~N}\right)$ labeling of ramet pairs at the seed-filling stage. In L. chinensis clonal populations, from the heading stage, the photosynthetic contribution of the functional leaves to seed production was much greater than that of the flag leaf; the photosynthetic capacity of both the functional leaves and the flag leaf all gradually declined. Vegetative ramets translocated their own resources to the connected reproductive ramets, and a large proportion of translocated resources were allocated to the leaf and stem to sustain life activities; increase in the number of connecting vegetative ramets increased floret number, seed number, seed-setting rate, inflorescence biomass, seed biomass, and reproductive allocation of reproductive ramets, and these parameters significantly and positively correlated with the biomass of connecting vegetative ramets. We conclude that the functional leaf rather than the flag leaf of $L$. chinensis is the primary contributor to seed production. Reproductive ramets adopt a strategy of growth first and reproduction later to allocate the translocated resources between the organs, but vegetative ramets are very advantageous for sexual reproduction under the tillering node connection form in L. chinensis. Overall, our study implies that vegetative ramets not only play an important role in the spatial expansion but also in the sexual reproduction of clonal plant populations.

Keywords: flag leaf, perennial herb, resource allocation, resource translocation, sexual reproduction, tillering node, vegetative ramet 


\section{INTRODUCTION}

Reproduction is an important link in the entire life history of plants, which is related to the formation, development, and evolution of plant populations. Many higher plant species are clonal organisms that have the capacity to propagate vegetatively by means of specialized organs such as rhizomes, stolons, bulbils, and rooting buds or reproduce sexually through seeds (Richards, 1986). Within a clonal plant, the offspring derived from vegetative propagation are specifically called "ramets" (Harper, 1977); they are physiologically potentially independent but share an identical genetic makeup. In contrast, the offspring generated by sexual reproduction are genetically diverse and better able to adapt to heterogeneous or changing environments (e.g., Maynard Smith, 1971), and they can spread over longer distances (Eckert, 2001). Under natural conditions, some clonal plant populations mainly rely on vegetative propagation to achieve recruitment and regeneration with infrequent recruitment from seeds (Cook, 1985; Eriksson, 1989, 1992), but sexual reproduction is vital for the long-term development of clonal populations.

There are two types of ramets widely distributed in clonal plant populations: vegetative ramets and reproductive ramets (Harper, 1977; Wang et al., 2017). Vegetative ramets refer to ramets that do not produce flowers and solely conduct vegetative growth, while reproductive ramets refer to ramets that enable sexual reproduction, flowering, and seed setting. Once a reproductive ramet initiates reproductive machinery via growth, a strong source-sink relationship is formed between the organs (Pan, 2012). Inflorescences are forming seeds and are a sink for accumulating nutrients; leaves can carry out photosynthesis and are a source for producing nutrients (Chang and Zhu, 2017; Burnett, 2019). In gramineous plants, the first leaf below the inflorescence is usually called the flag leaf (the last leaf to emerge), and the leaves at other positions of a plant are called functional leaves. Many studies concerning cereal crops have shown that the flag leaf is the primary contributor to sexual reproduction (Walpole and Morgan, 1972; Yoshida, 1972; Araus and Tapia, 1987). For example, Li et al. (1998) found that the upper leaves of the rice plant, particularly the flag leaf, provided more than $50 \%$ of the dry matter for grain filling. Lupton (1972) estimated by modeling approaches that at least $50 \%$ of the grain carbohydrate was derived from the flag leaf. However, the extent to which the flag leaf of clonal grass contributes to seed production during sexual reproduction is still unclear.

Ramets are usually connected to each other in clonal gramineous plants. Except for rhizome or stolon connections, tillering node connection is also a very common connection form between ramets. Under natural conditions, vegetative ramets may grow on the unelongated basal internodes of reproductive ramets, in which case the two types of ramets are interconnected through tillering nodes. Surprisingly, direct tests of the effect of vegetative ramets connected to tillering nodes on reproductive ramets appear to have focused mainly on cereal crops. Vegetative ramets can compete with reproductive ramets for solar energy, carbohydrates, and mineral nutrients, for example, nitrogen in rice (Nuruzzaman et al., 2000); thus, an increase in vegetative ramets may cause fewer nutrients to be directed to grain production. However, Ao et al. (2010) found that an increase in the number of vegetative ramets did not reduce the grain yield of rice. Similarly, many studies concerning wheat have also observed inconsistencies in the effects of vegetative ramets on grain production (Thorne and Wood, 1987; Zhou et al., 2007). However, it is not well known what effects of the number of vegetative ramets connected to tillering nodes on seed production in clonal grasses.

Leymus chinensis, a perennial rhizomatous forage grass, is often regarded as a constructive and dominant species across eastern areas of the Eurasian steppe (Zhu, 2004). Under natural conditions, L. chinensis primarily depends on vegetative propagation of rhizomes and tillering nodes to achieve population renewal and spatial expansion (Yang et al., 1995), and its capacity for sexual reproduction is rather weak. It has been reported that seed-setting rate is less than $25 \%$ on the average in natural grasslands, but varies greatly between individual ramets (Wang, 1998). Because of economical and ecological significance, L. chinensis has received considerable attention (Wang, 2001; Gao et al., 2014; Zhou et al., 2014; Yuan et al., 2016). Many studies have shown that seed production of $L$. chinensis can be influenced by external ecological factors, such as climate (Yang et al., 2000; Wang et al., 2003), water use (Song et al., 2003), nutrient uptake (Chen J.S. et al., 2013), and disturbance by human being and animals (Wang, 2000). However, how vegetative ramets within the clone affect seed production of L. chinensis has less been studied.

Here, we grew L. chinensis in a field homogeneous environment and measured the growth characteristics of different aged leaves of reproductive ramets, dynamically measured the net photosynthetic rate of different aged leaves and organ biomass, determined the phenotypic characteristics of reproductive ramets which had different numbers $(1,2,3, \geq 4)$ of connecting vegetative ramets. We labeled the vegetative ramets with isotope $\left({ }^{15} \mathrm{~N}\right)$ at the seed-filling stage to verify whether vegetative ramets translocate resources toward the connected reproductive ramets. The objectives of our study were (1) to explore the contribution of the flag leaf to seed production during sexual reproduction and (2) to assess the effect of the number of vegetative ramets connected to tillering nodes on sexual reproductive performance. Here, we hypothesize that during sexual reproduction, (1) the photosynthesis of flag leaves will contribute the most to seed production, and (2) increase in the number of vegetative ramets connected to tillering nodes will reduce sexual reproductive performance.

\section{MATERIALS AND METHODS}

\section{Study Area}

The study was conducted at the Grassland Ecological Research Station, Northeast Normal University, Jilin Province, China $\left(44^{\circ} 38^{\prime} \mathrm{N}, 123^{\circ} 41^{\prime} \mathrm{E}\right)$. The study site is located in the southern 
region of the Songnen Plain, where the climate is semihumid and semiarid, with hot, rainy monsoonal summers and cold, arid winters. The mean annual temperature is $4.6-6.4^{\circ} \mathrm{C}$. The mean annual precipitation is $300-450 \mathrm{~mm}$, mostly falling in the growing season, and the annual evaporation is $1200-1400 \mathrm{~mm}$. The growing season with a frost-free period is approximately 130-165 days (Li et al., 2018; Guo et al., 2020).

\section{Study Species}

Leymus chinensis, a perennial forage grass, has high nutritional value and good palatability. L. chinensis has strong ecological adaptability and tolerance to drought, salt-alkaline, and lowtemperature conditions (Bai et al., 2004; Jin et al., 2008; Chen S. et al., 2013); thus, it often forms L. chinensis steppes and meadows as a dominant species. It is widely distributed in the eastern part of the Eurasian steppe zone, including the southern and central areas of Russia, the People's Republic of Mongolia, the Inner Mongolian Plateau of China, and the Northeast China Plain (Kuo, 1987). The clonal ramets of L. chinensis are interconnected via rhizomes or tillering nodes (Guo et al., 2020). It is common for L. chinensis to have one reproductive ramet and different numbers of vegetative ramets on one tillering node. On the Songnen Plain, L. chinensis usually begins returning green in early April, heading in midto-late May, flowering in June, and maturing in mid-July (Zhu, 2004).

\section{Experimental Platform}

A total of 30 experimental plots of L. chinensis were established at the beginning of May 2015. Adjacent plots were at least $2 \mathrm{~m}$ apart, and the area of each plot $(2 \mathrm{~m} \times 2 \mathrm{~m})$ was $4 \mathrm{~m}^{2}$. Vegetative ramets of $L$. chinensis of a similar size (ramet height: $20.9 \pm 0.3 \mathrm{~cm}$, mean $\pm \mathrm{SE}$ ) were sampled from the same natural clone in the study area, and then nine ramets were transplanted into each plot with rows $0.5 \mathrm{~m}$ apart and $0.5 \mathrm{~m}$ between ramets. Ramets were only watered in the early stage of transplanting to ensure survival. During the entire experimental period, the plots were just weeded regularly and without any management of irrigation and fertilization, the ramets were not influenced by any insect pests or diseases. The experimental site was originally agricultural land. The soil type is sandy loam (Li et al., 2001; Guo et al., 2020; Yuan et al., 2020). The soil of the top 20-cmthick soil layer was homogenous, and the total organic $\mathrm{C}$ content, total $\mathrm{N}$ content and total $\mathrm{P}$ content were $6.23 \pm 0.55 \mathrm{~g} \mathrm{~kg}^{-1}$, $1.01 \pm 0.04 \mathrm{~g} \mathrm{~kg}^{-1}$, and $0.74 \pm 0.02 \mathrm{~g} \mathrm{~kg}^{-1}$, respectively. The $\mathrm{pH}$ was $8.37 \pm 0.03$, and the electrical conductivity was $70.85 \pm 2.61 \mu \mathrm{S} \mathrm{cm}^{-1}$.

In 2015, the transplanted ramets of L. chinensis in each experimental plot only conducted vegetative propagation, and there was no reproductive ramet in the L. chinensis population. In 2016, a few reproductive ramets appeared in several experimental plots. In 2017, there were many reproductive ramets in each experimental plot. Therefore, this study started from the third year after the establishment of experimental plots. The preliminary investigation showed that approximately $93.3 \%$ of reproductive ramets had three leaves, and only $6.7 \%$ had four leaves in experimental plots. Thus, reproductive ramets with three leaves were chosen for all experiments in this study.

\section{Leaf Growth Characteristics, Photosynthetic Rate and Organ Biomass}

To assess the effects of growth time on the leaf net photosynthetic rate and organ biomass of reproductive ramets, periodic measurements and samplings were conducted. A total of 10 plots were randomly selected from 30 plots to mark the samples on May 20, 2017. Twenty-two reproductive ramets that were healthy and uniform in height and whose inflorescences were fully exposed $2 \mathrm{~cm}$ away from the flag leaves were randomly selected and marked in each plot. One of 22 ramets in each plot was used as a fixed sample ramet to measure leaf photosynthetic rate, and the remaining 21 ramets were used to measure organ biomass.

At the early heading stage of $L$. chinensis populations, the net photosynthetic rate of all aged leaves on each marked ramet was measured every 7 days using a LI-6400 portable photosynthesis system (Li-Cor Biosciences, Lincoln, NE, United States) under the conditions of saturating light intensity $\left(1500 \mu \mathrm{mol} \mathrm{m} \mathrm{m}^{-2} \mathrm{~s}^{-1}\right)$ and fixed $\mathrm{CO}_{2}$ concentration (400 $\mu \mathrm{mol} \mathrm{mol}{ }^{-1}$ ). The measurements started on May 26 and ended on July 7 when the leaves turned distinctly yellow. According to the birth order of the leaves, the leaves were recorded as 1a-leaf, 2a-leaf, and 3a-leaf in order from the base to the top of the reproductive ramet. The 1a-leaf and $2 \mathrm{a}$-leaf were functional leaves, and the 3a-leaf was the flag leaf.

The measurements of organ biomass were conducted simultaneously with photosynthesis measurements. For each measurement, only the aboveground part of the ramet was harvested, and a total of three reproductive ramets were randomly collected from the marked ramets with tags in each plot and dried to a constant weight at $65^{\circ} \mathrm{C}$. Leaf biomass, stem biomass and inflorescence biomass were measured. All leaves of each ramet at the 5th measurement on June 23 (at the seedfilling stage, the most critical stage of sexual reproduction) were scanned on a flatbed scanner (CanoScan LiDE 110, Canon, Japan) to calculate the leaf area.

\section{Effects of the Number of Vegetative Ramets Connected to Tillering Nodes on Sexual Reproductive Performance}

To assess the effects of the number of vegetative ramets connected to tillering nodes on sexual reproductive performance in a field homogeneous environment, grading samplings were conducted in both 2017 and 2018. First, at the early heading stage of $L$. chinensis each year, we used colored tags to mark those reproductive ramets whose inflorescence top reached approximately $2 \mathrm{~cm}$ over the flag leaf sheath and that were connected to different numbers $(1,2,3$, and $\geq 4)$ of vegetative ramets by tillering nodes at the edge of each plot (Figure 1A). There was only one reproductive ramet per gradient in each plot. Five plots were abandoned because some gradients were not found. In fact, the reproductive ramets that were connected to zero vegetative ramets via tillering nodes exist at the edge of few experimental plots, due to its extremely low numbers did not 


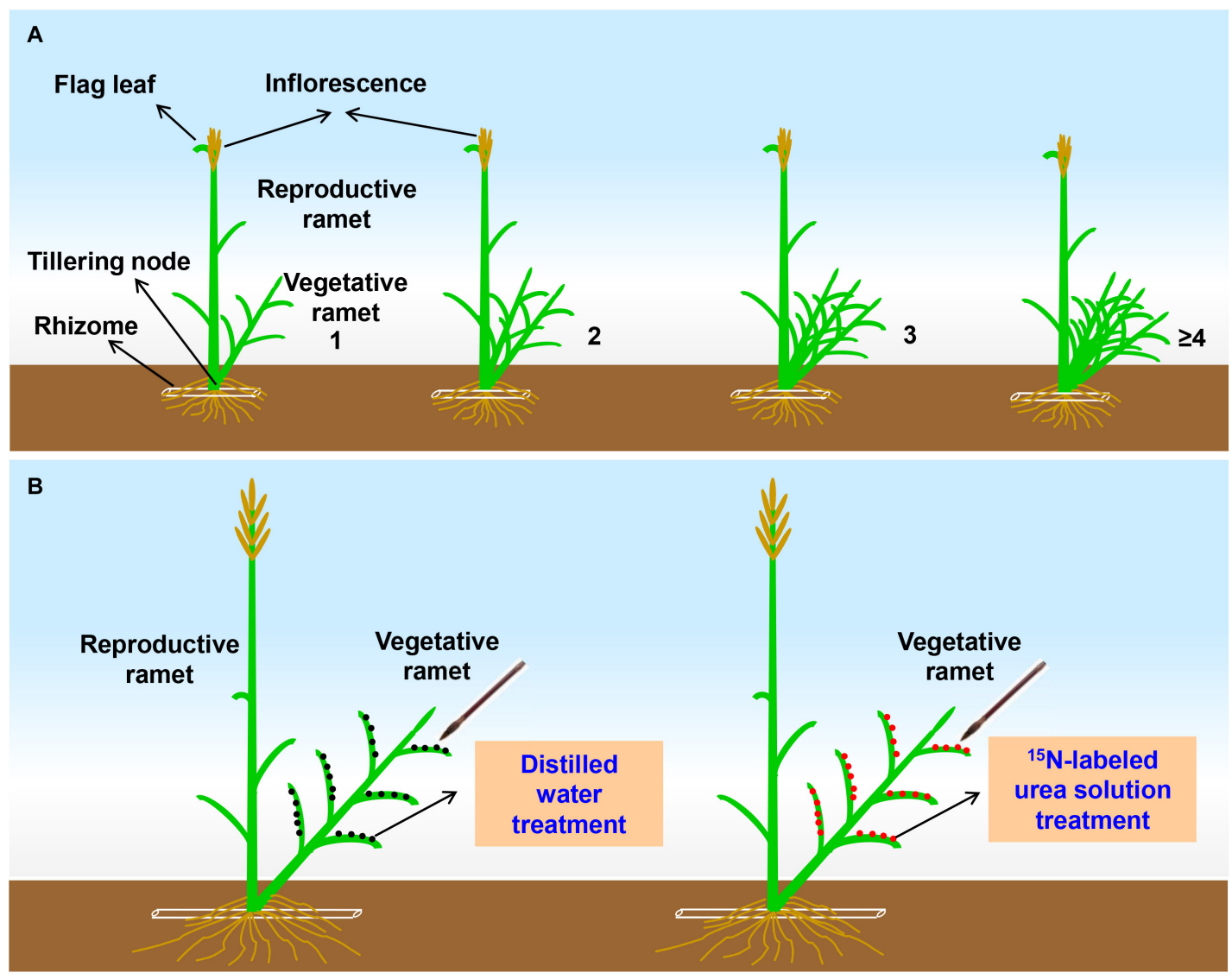

FIGURE 1 | (A) Schematic representation of the tagging experimental design at the early heading stage of Leymus chinensis. The Arabic numerals represent the number of vegetative ramets connected to a tillering node of the reproductive ramet. In each gradient, inflorescence top of the reproductive ramet reaches approximately $2 \mathrm{~cm}$ over the flag leaf sheath. (B) Schematic representation of the stable-isotope $\left({ }^{15} \mathrm{~N}\right)$ labeling experimental design at the seed-filling stage of Leymus chinensis. Each ramet pair consists of one reproductive ramet and one vegetative ramet connected by a tillering node (which refers to unelongated basal internode of the ramet).

meet the requirement sample size for experiment, so it was not taken into account in this study.

At the seed-maturing stage, only the aboveground parts of both marked reproductive ramets and their connected vegetative ramets were harvested together. The inflorescence length was measured, and the floret number and seed number were counted. Inflorescence biomass, seed biomass, reproductive ramet biomass, leaf biomass, and total biomass of vegetative ramets were measured after drying in an oven at $65^{\circ} \mathrm{C}$ for $48 \mathrm{~h}$.

\section{Stable-Isotope Labeling}

To verify whether vegetative ramets translocate their own resources to the connected reproductive ramets during sexual reproduction, in situ labeling of vegetative ramets with ${ }^{15} \mathrm{~N}$ by foliar brushing (Putz et al., 2011; Wang et al., 2017) was carried out at the seed-filling stage of L. chinensis in late June of both 2017 and 2018. Four plots were randomly selected for ${ }^{15} \mathrm{~N}$ labeling each year. Two ramet pairs with similar sizes (one ramet pair for the ${ }^{15} \mathrm{~N}$ labeling treatment and another for the control treatment) were randomly chosen at the edge of each plot, and each ramet pair consisted of one reproductive ramet and one vegetative ramet connected by a tillering node (Figure 1B). Two ramet pairs were at least $50 \mathrm{~cm}$ apart. $A{ }^{15} \mathrm{~N}$ labeling experiment was conducted in the following year in randomly selected remaining plots to avoid cross-contamination.

The ${ }^{15} \mathrm{~N}$ labeling experiment was performed on consecutive sunny days so that the ${ }^{15} \mathrm{~N}$ label on the leaves of ramets would not be washed into the soil. Before labeling, the soil surface was covered with plastic film to prevent polluting soil, and the reproductive ramet of each ramet pair was kept in a plastic film cylinder sleeves to avoid contamination. One milliliter of ${ }^{15} \mathrm{~N}$-labeled urea (made at Shanghai Research Institute of Chemical Industry, China) solution with a urea concentration of $0.02 \mathrm{~g} \mathrm{ml}^{-1}$ and a ${ }^{15} \mathrm{~N}$ abundance of $5.18 \%$ was applied to all leaves of the vegetative ramet of each ramet pair (Figure 1B) following the protocol from Guo et al. (2020). Labeling was performed once a day for 3 days. An equal volume of distilled water was used instead of the ${ }^{15} \mathrm{~N}$-labeled urea solution in the control treatment (Figure 1B).

On the 5 th day of ${ }^{15} \mathrm{~N}$ labeling, the aboveground reproductive ramets both in the labeling treatment and control treatment in each plot were harvested and separated into three parts, 
namely, the inflorescence, stem, and leaf. Each plant tissue was de-enzymed at $105^{\circ} \mathrm{C}$ for $30 \mathrm{~min}$ and then dried at $65^{\circ} \mathrm{C}$ for $48 \mathrm{~h}$. We then measured the dry mass of each tissue and ground the samples to a fine powder in a ball mill (MM 400 Retsch, Germany). For each sample, approximately $3 \mathrm{mg}$ of solid powder was tightly wrapped in a capsule and then directly evaluated with an Isoprime 100 isotope ratio mass spectrometer (Elementar, Langenselbold, Germany) coupled to a vario EL cube elemental analyzer (Elementar, Langenselbold, Germany). We measured N content and $\delta^{15} \mathrm{~N}$. The $\delta^{15} \mathrm{~N}$ was expressed as follows:

$$
\delta^{15} \mathrm{~N}(\%)=\left(R_{\text {sample }} / R_{\text {standard }}-1\right) \times 1000
$$

where $R_{\text {sample }}$ and $R_{\text {standard }}$ represent the ${ }^{15} \mathrm{~N} /{ }^{14} \mathrm{~N}$ in a sample and ${ }^{15} \mathrm{~N} /{ }^{14} \mathrm{~N}$ in atmospheric $\mathrm{N}_{2}$, respectively. The ${ }^{15} \mathrm{~N} /{ }^{14} \mathrm{~N}$ in atmospheric $\mathrm{N}_{2}$ is constant at 0.00368 .

The amount of translocated ${ }^{15} \mathrm{~N}$ from the labeled vegetative ramet toward each tissue of the unlabeled reproductive ramet was calculated by the following equations:

$$
F(\%)=\left[R_{\text {sample }} /\left(R_{\text {sample }}+1\right)\right] \times 100
$$

$$
\begin{gathered}
\text { Translocated }{ }^{15} \mathrm{~N} \text { amount }=W_{\text {dry-labeling }} \times B_{\text {labeling }} \\
\times\left(F_{\text {labeling }}-F_{\text {control }}\right)
\end{gathered}
$$

where $W_{\text {dry }}$ and $B$ represent dry mass and nitrogen content per unit mass of a sample in the labeling treatment, respectively. $F_{\text {labeling }}$ and $F_{\text {control }}$ represent the $F$-ratio of a sample in the labeling treatment and control treatment, respectively.

\section{Statistical Analysis}

All data analyses were carried out using SPSS 22.0 statistical software (SPSS Inc., Chicago, IL, United States). Data normality was tested with the Kolmogorov-Smirnov test, and variance homogeneity was tested with Levene's test. The significance level was set at $P<0.05$.

The length, width and area of flag leaves and functional leaves were calculated by WinFOLIA Pro 2011 software (Regent Instruments, Québec city, QC, Canada). One-way ANOVA was used to assess the effects of leaf age on the leaf length, width and area of reproductive ramets; to examine the effect of organ on the amount of translocated ${ }^{15} \mathrm{~N}$; and to examine the effects of the number of connected vegetative ramets on sexual reproductive performance. Significant differences in the means were compared with Duncan's multiple-range test. An independent-samples $t$-test was used to test the differences in leaf $\delta^{15} \mathrm{~N}$, stem $\delta^{15} \mathrm{~N}$, and inflorescence $\delta^{15} \mathrm{~N}$ between the ${ }^{15} \mathrm{~N}$ labeling and control treatments. Sexual reproductive performance consisted of floret number, seed number, seed-setting rate (percentage of seed number in floret number), inflorescence length, inflorescence biomass, seed biomass, reproductive allocation 1 (percentage of inflorescence biomass in ramet biomass), and reproductive allocation 2 (percentage of seed biomass in ramet biomass).

Repeated-measures ANOVA were used to assess the effects of leaf age and growth time on photosynthetic rate and photosynthetic contribution and to assess the effects of organ type and growth time on organ biomass; the results were reported using the Greenhouse-Geisser correction when Mauchly's test of sphericity was violated. The photosynthetic contribution of individual leaves of reproductive ramets was calculated as follows:

$$
P C_{i}(\%)=\left(P_{i} \times A_{i}\right) /\left[\sum_{i=1}^{3}\left(P_{i} \times A_{i}\right)\right] \times 100
$$

where $P_{i}$ and $A_{i}$ are the net photosynthetic rate and leaf area of the $i(1 \mathrm{a}, 2 \mathrm{a}$, and $3 \mathrm{a})$ leaf of reproductive ramets.

To reveal the rules of change in the sexual reproductive performance with respect to differences in the leaf biomass and total biomass of connected vegetative ramets, the eight variables were regressed based on the difference in the leaf biomass and total biomass of connected vegetative ramets using logarithmic, power, exponential, and linear functions in both years, and the model with the lowest Akaike information criterion (AIC) value from these four was considered the best-fitting model (Sugiura, 1978). The growth time was calculated starting from returning green of L. chinensis (April 5, 2017), and the corresponding growth time of seven measurement dates was $51,58,65,72,79$, 86 , and 93 days.

\section{RESULTS}

\section{Growth Characteristics of the Flag Leaf and Functional Leaf}

At the seed-filling stage, the leaf length, leaf width and leaf area of both 1a- and 2a-functional leaves of the reproductive ramets were significantly larger than those of the flag leaf. The average leaf areas of the 1a-functional leaf (accounting for $53.0 \%$ of the total leaf area) and the 2a-functional leaf (accounting for 38.6\% of the total leaf area) were 6.3 times and 4.6 times as large as that of the flag leaf (accounting for $8.4 \%$ of the total leaf area), respectively (Table 1). These results showed that the flag leaf was short and narrow, while the functional leaves were long and wide.

\section{Photosynthetic Rate of the Flag Leaf and Functional Leaf}

The net photosynthetic rate of the 2a-functional leaf of reproductive ramets was higher than that of the other two leaves in the 1st and 2nd measurements, while the net photosynthetic rate of the flag leaf was higher than that of the other two leaves

TABLE 1 | Growth characteristics of flag leaves and functional leaves of reproductive ramets in Leymus chinensis (means $\pm \mathrm{SE}, n=10$ ).

\begin{tabular}{lccc}
\hline Leaf age & Length $\mathbf{( c m )}$ & Width $\mathbf{( c m )}$ & Area $\mathbf{( c m}^{\mathbf{2}} \mathbf{~}$ \\
\hline 3a-flag leaf & $3.52 \pm 0.15 \mathrm{c}$ & $0.34 \pm 0.01 \mathrm{~b}$ & $0.81 \pm 0.04 \mathrm{c}$ \\
2a-functional leaf & $11.83 \pm 0.33 \mathrm{~b}$ & $0.46 \pm 0.01 \mathrm{a}$ & $3.73 \pm 0.14 \mathrm{~b}$ \\
1a-functional leaf & $16.12 \pm 0.58 \mathrm{a}$ & $0.48 \pm 0.01 \mathrm{a}$ & $5.13 \pm 0.16 \mathrm{a}$ \\
Total & - & - & $9.67 \pm 0.27$
\end{tabular}

Different lowercase letters indicate significant differences $(P<0.05)$ between the leaf ages (a, age). 
from the 3 rd measurement to the end. The net photosynthetic rate of the la-functional leaf was always the lowest and decreased early at the last measurement (Figure 2). With the increase in growth time, the net photosynthetic rate of these three leaves showed a decreasing trend, and the net photosynthetic rate of the 1a-functional leaf and flag leaf significantly decreased from the 3rd measurement, while that of the 2a-functional leaf decreased from the 2 nd measurement. The average net photosynthetic rate of both the flag leaf and 2a-functional leaf was significantly higher than that of 1a-functional leaf (Figure 2).

\section{Photosynthetic Contribution of the Flag Leaf and Functional Leaf to Seed Production}

In all the measurements, the photosynthetic contribution of the 2a-functional leaf to seed production was significantly greater than that of the other two leaves, except that the 1a-functional leaf died prematurely and its photosynthetic contribution decreased to zero in the last measurement (Figure 3). The photosynthetic contributions of the flag leaf and 2a-functional leaf to seed production both showed an increasing trend with the increase in growth time on the whole, while that of the 1a-functional leaf was the greatest in the 2 nd measurement and the least in the last measurement. The average photosynthetic contribution to seed production of the $2 \mathrm{a}$-functional leaf was significantly greater than that of the other two leaves, while that of the flag leaf was significantly less than that of the other two leaves (Figure 3).

\section{Variation in the Organ Biomass of Reproductive Ramets Over Time}

In all the measurements, stem biomass was significantly greater than leaf biomass and inflorescence biomass, while leaf biomass was the smallest (Figure 4). With increasing growth time, both leaf biomass and stem biomass first increased and then decreased, while inflorescence biomass showed an increasing trend. For leaf biomass, there was no significant difference between the first three and the last four measurements. Stem biomass significantly increased in the 2 nd measurement, but there was no significant difference among the last six measurements. Inflorescence biomass significantly increased in the first three measurements, but there was no significant difference among the last four measurements. The total biomass of individual reproductive ramets significantly increased in the first three measurements and then remained relatively stable (Figure 4).

\section{Effects of the Number of Vegetative Ramets Connected to Tillering Nodes on Sexual Reproductive Performance}

With an increase in the number of vegetative ramets connected to tillering nodes, the inflorescence biomass, floret number, seed number, seed-setting rate, seed biomass, reproductive allocation 1 , and reproductive allocation 2 of $L$. chinensis showed an increasing trend on the whole over the two consecutive years (Figures 5B1-H1, B2-H2), whereas the inflorescence length did not (Figures 5A1, A2). The seed number, seed-setting rate, seed biomass, reproductive allocation 1 , and reproductive allocation 2 of the reproductive ramets connected to $\geq 4$ vegetative ramets were 1.0 times, $85.6 \%, 92.2 \%, 15.3 \%$, and $91.0 \%$ higher, respectively, than those of the reproductive ramets connected to one vegetative ramet in 2017 and 1.1 times, 80.9\%, 1.4 times, $15.2 \%$, and $87.2 \%$ higher, respectively, than those of the reproductive ramets connected to one vegetative ramet in 2018. These results demonstrated that inflorescence length was relatively stable over the two consecutive years, whereas the other seven characteristics fluctuated markedly.

With increasing leaf biomass (Figures 6A1-H1) or total biomass (Figures 6A2-H2) of the vegetative ramets connected to tillering nodes, the inflorescence length, inflorescence biomass, floret number, seed number, seed-setting rate, seed biomass, reproductive allocation 1 , and reproductive allocation 2 of the reproductive ramet of $L$. chinensis increased linearly. Except for those involving the inflorescence length in 2017, all other relationships reached a significant level.

\section{Transfer of ${ }^{15} \mathrm{~N}$ From Vegetative Ramets to Connected Reproductive Ramets}

At the seed-filling stage, the leaf $\delta^{15} \mathrm{~N}$, stem $\delta^{15} \mathrm{~N}$, and inflorescence $\delta^{15} \mathrm{~N}$ of reproductive ramets in the ${ }^{15} \mathrm{~N}$ labeling treatment were all significantly greater than those in the control treatment over the two consecutive years (Table 2). The amount of translocated ${ }^{15} \mathrm{~N}$ in the stem of reproductive ramets was significantly greater than that in the leaf and inflorescence, and the amount of translocated ${ }^{15} \mathrm{~N}$ in the inflorescence was the least (Table 3).

\section{DISCUSSION}

\section{Photosynthetic Contribution of the Flag Leaf and Functional Leaf to Seed Production}

The main driving force for the growth and biomass production of plants is photosynthesis, which provides the carbon and energy required for the synthesis of organic compounds necessary for development (Field et al., 1998; Nowicka et al., 2018). In clonal plant populations, seed production primarily relies on the photosynthetic source-sink relationship. Leaves are primarily involved in photosynthesis and are material producers and exporters. The number and size of leaves determine a plant's photosynthetic potential and play important roles in determining plant yield, stress responses and disease resistance (Pérez-Pérez et al., 2010; Yang et al., 2015). In the present study, in L. chinensis populations growing in a field homogeneous environment, only $6.7 \%$ of reproductive ramets had four leaves, and $93.3 \%$ had three leaves. Among the reproductive ramets with three leaves, the flag leaf area was significantly smaller than the functional leaf area (Table 1). The average area of the flag leaf $\left(0.81 \mathrm{~cm}^{2}\right)$ was only $8.4 \%$ of the total leaf area $\left(9.67 \mathrm{~cm}^{2}\right)$, reflecting the very small flag leaf of L. chinensis. This is very different from the leaf growth characteristics of cereal crops. It has been reported that wheat (Triticum aestivum) generally has 6-8 leaves (Berry et al., 1980), and the areas of the top three leaves are approximately the same in size (approximately $20 \mathrm{~cm}^{2}$ on average) (Yin et al., 2019); 


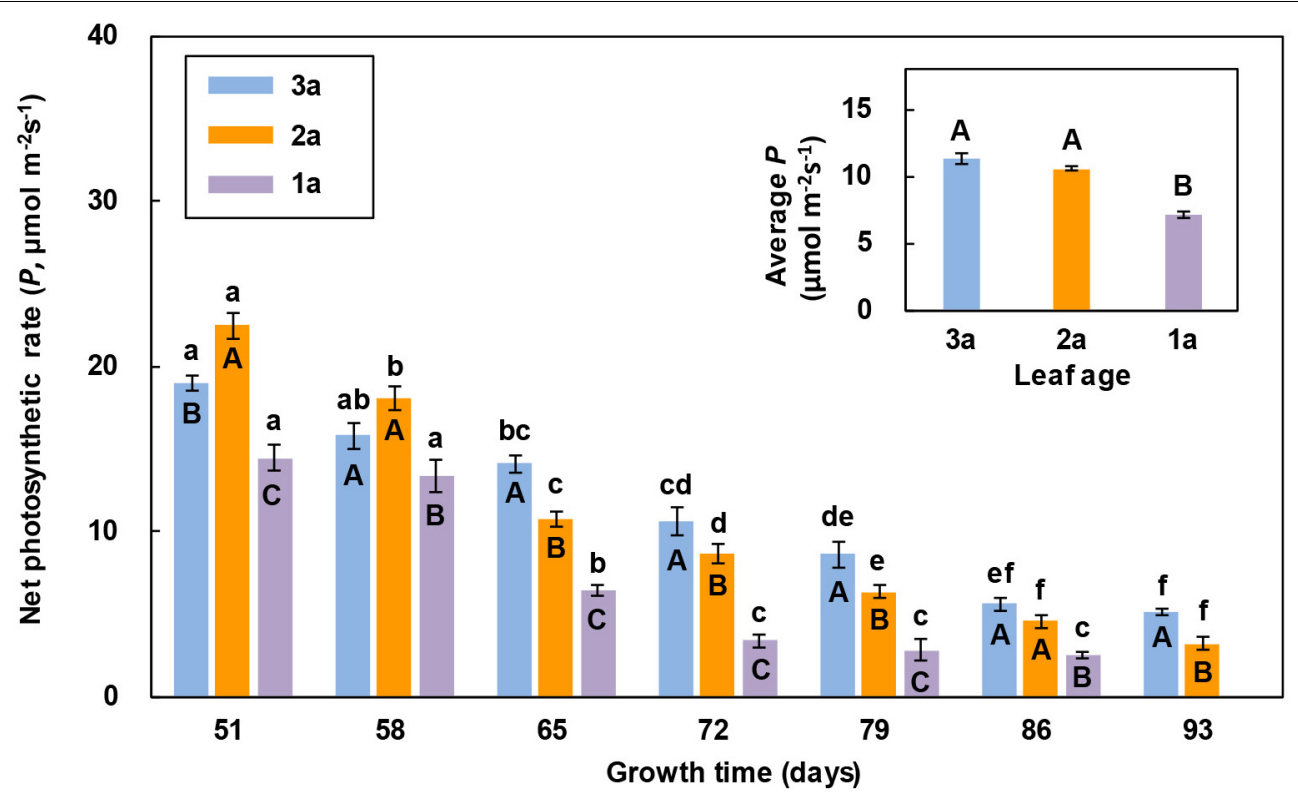

FIGURE 2 | Comparison of the net photosynthetic rate $(P)$ of three leaves of reproductive ramets over time (means \pm SE, $n=10)$ in Leymus chinensis. Different lowercase letters indicate significant differences $(P<0.05)$ between the growth times for the same leaf age; different capital letters indicate significant differences $(P<0.05)$ between the leaf ages for the same growth time. The average $P$ of seven growth times is presented as an inset figure. The dates corresponding to the seven growth times are May 26, June 2, June 9, June 16, June 23, June 30, and July 7 in 2017.



FIGURE 3 | Comparison of the photosynthetic contribution percentage $(P C)$ of three leaves of reproductive ramets over time (means \pm SE, $n=10$ ) in Leymus chinensis. Different lowercase letters indicate significant differences $(P<0.05)$ between the growth times for the same leaf age; different capital letters indicate significant differences $(P<0.05)$ between the leaf ages for the same growth time. The average $P C$ of seven growth times is presented as an inset figure. The dates corresponding to the seven growth times are May 26, June 2, June 9, June 16, June 23, June 30, and July 7 in 2017.

rice has 9-20 leaves (Yin and Kropff, 1996), and the average areas of the flag leaf and the top second leaf are 43.6 and $51.8 \mathrm{~cm}^{2}$ (Li et al., 1998). Thus, both the number and size of leaves of $L$. chinensis are evidently less than those of wheat and rice. A large number of studies have confirmed that there is a significant positive correlation between flag leaf area and grain yield (Dhiman et al., 1980; Yue et al., 2006; Sedeek et al., 2009). Therefore, the extremely small leaf area of reproductive ramets may be related to their weak capacity for seed production in L. chinensis. 


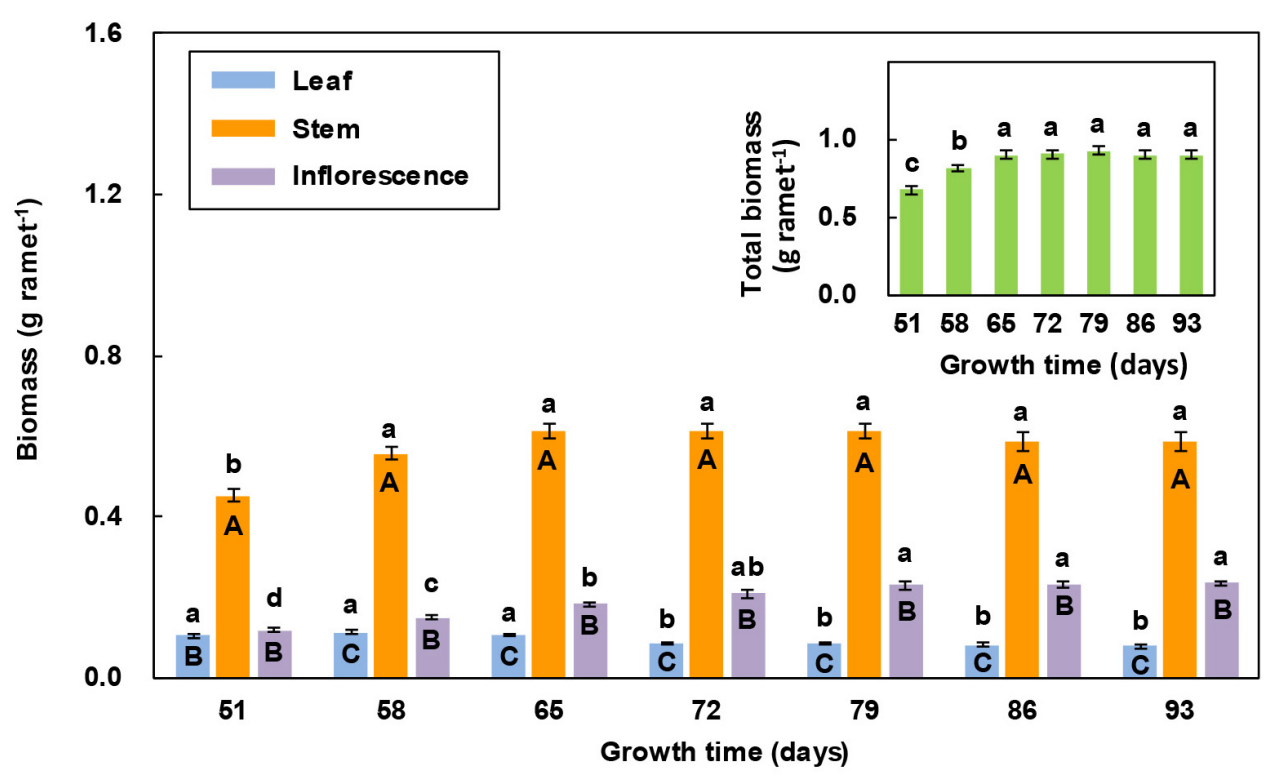

FIGURE 4 | Comparison of the biomass of three organs of reproductive ramets over time (means \pm SE, $n=10$ ) in Leymus chinensis. Different lowercase letters indicate significant differences $(P<0.05)$ between the growth times for the same organ; different capital letters indicate significant differences $(P<0.05)$ between the organ types for the same growth time. The total biomass of three organs is presented as an inset figure. The dates corresponding to the seven growth times are May 26, June 2, June 9, June 16, June 23, June 30, and July 7 in 2017.

The leaf photosynthetic rate is an important physiological parameter to determine the dry mass production, which reflects the ability of a leaf to assimilate $\mathrm{CO}_{2}$. In this study, we found that the net photosynthetic rate of the 2a-functional leaf of reproductive ramets was higher than that of the other two leaves in the first two measurements (Figure 2), indicating that the 2a-functional leaf was the most photosynthetically active and had the strongest ability to assimilate $\mathrm{CO}_{2}$ at the heading stage. However, from the 3rd measurement to the end, the net photosynthetic rate of the flag leaf was higher than that of the other two leaves (Figure 2), indicating that the flag leaf was the most photosynthetically active from the flowering to seed maturity stages. When the leaf area was combined with the net photosynthetic rate, the photosynthetic contribution of the flag leaf was always lower than that of the other two functional leaves (Figure 3). This finding does not agree with our first hypothesis, mainly because the flag leaf area of L. chinensis is particularly small, which weakens its photosynthetic rate advantage. Our result is inconsistent with the findings in cereal crops such as wheat and rice that photosynthesis of the flag leaf is the primary contributor to grain yield (Walpole and Morgan, 1972; Yoshida, 1972; Araus and Tapia, 1987; Li et al., 1998). This also means that the flag leaf of $L$. chinensis does not have the special mass production function of the flag leaf of cereal crops; instead, the functional leaf is the primary contributor to seed production.

\section{Senescence of the Flag Leaf and Functional Leaf}

The leaf photosynthetic rate is also an important parameter representing leaf vigor (Humbeck et al., 1996; Wingler et al.,
1998). In this study, the net photosynthetic rate of the flag leaf and functional leaves of reproductive ramets decreased gradually with increasing growth time from the heading stage (Figure 2), implying that the vigor of the flag leaf and functional leaves gradually declined and natural senescence occurred in all leaves. Senescence is the final stage of leaf development in plants. In leaf senescence, the most obvious outward sign is leaf yellowing, yet the most remarkable inner event is the disintegration of the photosynthetic apparatus in chloroplasts and the degradation of chlorophyll, leading to a concomitant decrease in photosynthetic activity (Woolhouse, 1987; Zheng et al., 2008). However, the senescence rate varies among leaves at different leaf positions on the same plant. Rousseaux et al. (1996) reported that artificial far-red enrichment of the light penetrating through the canopy easily accelerated senescence of the lower rather than the upper leaves in Helianthus annuus. When all the leaves of the plant are exposed to the same light conditions, the oldest ones senesce most quickly (Terashima et al., 2005). However, when certain leaves of the plant are shaded, such leaves senesce more quickly (Weaver and Amasino, 2001). We found that the net photosynthetic rate of the flag leaf was higher than that of the other two functional leaves in L. chinensis during growth for between 65 and 93 days (Figure 2), showing that the process of leaf senescence was delayed in the flag leaf and much slower than that in the 1a-functional leaf in particular. Some studies have clearly indicated that the difference in the red light to far-red light (R/FR) ratio received by leaves is related to leaf senescence (Anten et al., 2000; Smith, 2000; Terashima et al., 2005). In upright plants, young leaves (i.e., the flag leaf and 2 a-functional leaf in this study) shade old leaves (i.e., 1afunctional leaf in this study); therefore, the $\mathrm{R} / \mathrm{FR}$ ratio received by 


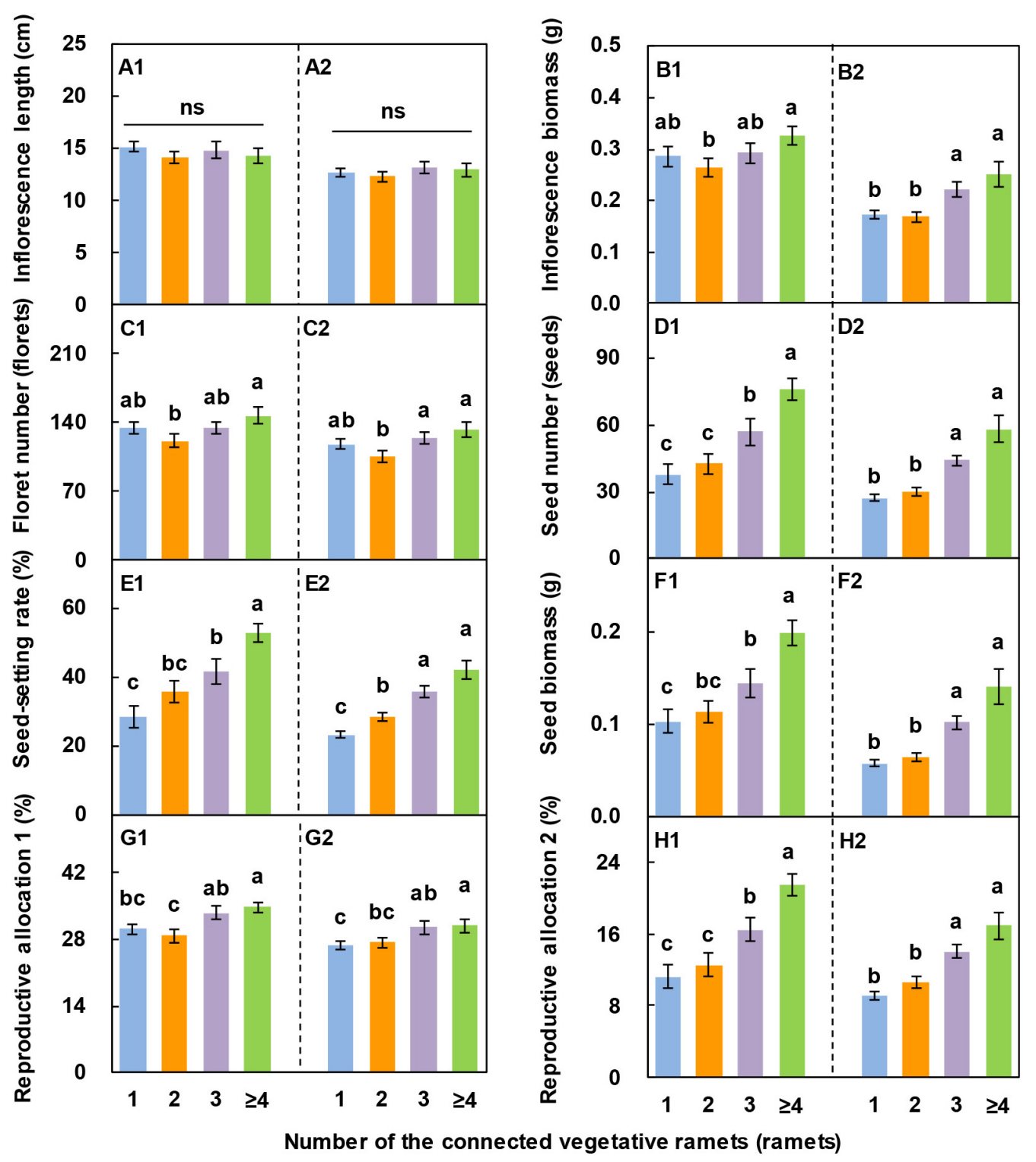

FIGURE 5 | Effects of the number of vegetative ramets connected to tillering nodes on sexual reproductive characteristics in Leymus chinensis populations over two consecutive years (2017, A1-H1; 2018, A2-H2). Data are the means \pm SE $(n=25)$. Different lowercase letters indicate significant differences $(P<0.05)$ between different numbers of vegetative ramets, and ns indicates that there is no significant difference $(P>0.05)$ between different numbers of vegetative ramets.

the old leaves decreases (Terashima et al., 2005), which promotes leaf senescence.

\section{Allocation of Translocated Resources Between Organs of Reproductive Ramets}

Isotope labeling technique is an effective method to explore resources translocation between connected ramets of clonal plants (Zhang et al., 2002). In this study, when the vegetative ramets were labeled with ${ }^{15} \mathrm{~N}$ at the seed-filling stage in clonal populations of $L$. chinensis growing in a field homogeneous environment, a significantly larger amount of ${ }^{15} \mathrm{~N}$ than the background value was detected in the connected reproductive ramets over the two consecutive years (Table 2). This result suggests that vegetative ramets can provide the connected reproductive ramets with resources at the most critical stage of sexual reproduction in L. chinensis. A study concerning the perennial stoloniferous grass Agrostis stolonifera found that at the beginning of daughter establishment, the amount of ${ }^{15} \mathrm{~N}$ translocated toward daughters was higher than that of ${ }^{15} \mathrm{~N}$ translocated toward mothers; when daughters reached the size of mothers, the amount of ${ }^{15} \mathrm{~N}$ translocated toward mothers was higher than that of ${ }^{15} \mathrm{~N}$ translocated toward daughters, indicating that the amount of translocated ${ }^{15} \mathrm{~N}$ was significantly affected by the direction of translocation and the developmental 

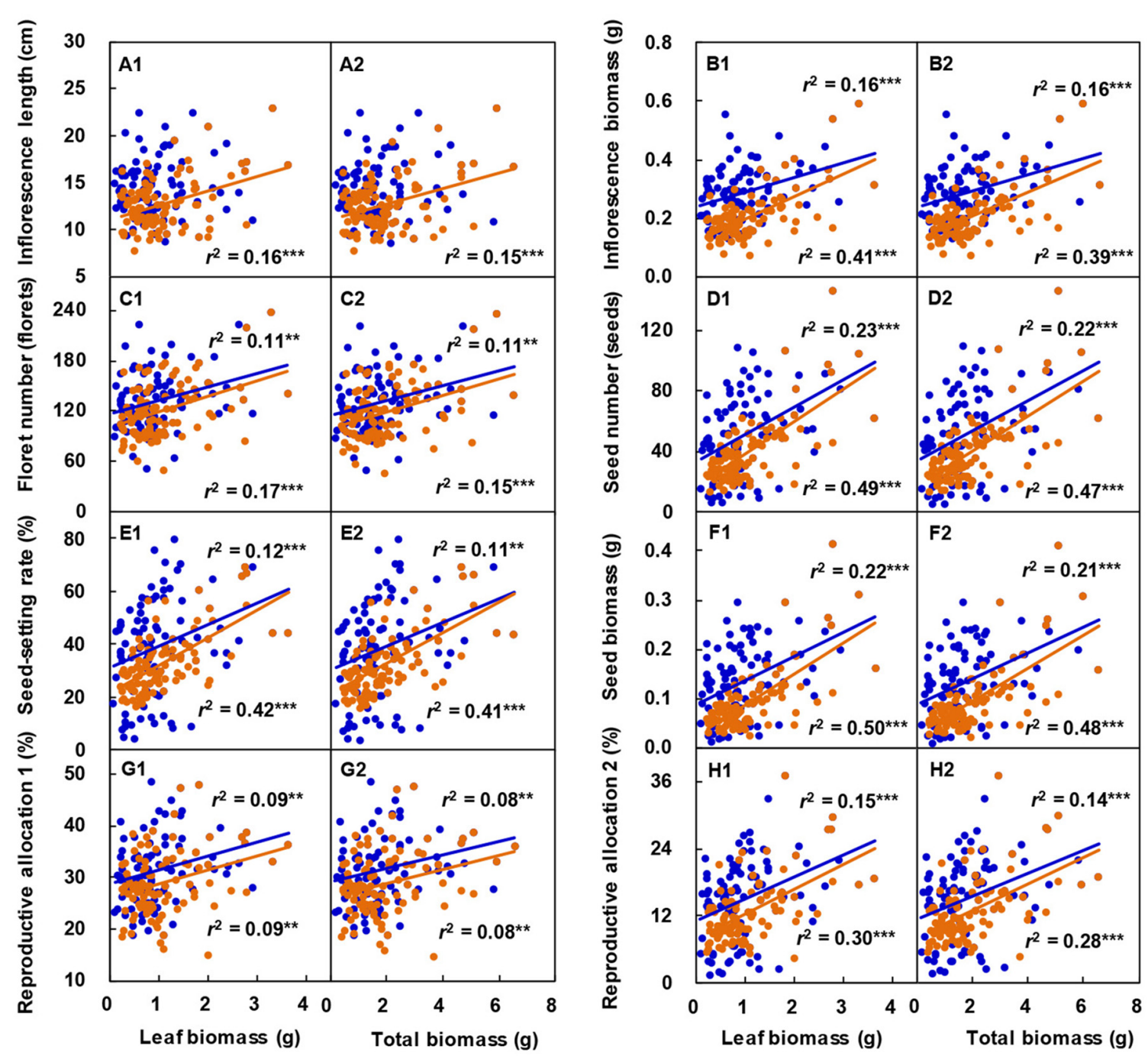

FIGURE 6 | Correlation between the sexual reproductive characteristics and both leaf biomass (A1-H1) and total biomass (A2-H2) of vegetative ramets connected to tillering nodes in Leymus chinensis populations over two consecutive years. The colored circles and lines represent observed data and their fitting lines in 2017 (blue, $n=100$ ) and 2018 (orange, $n=100$ ). ${ }^{\star \star} P<0.01$; ${ }^{\star \star \star} P<0.001$.

status of daughter ramets (Duchoslavová and Jansa, 2018). However, above the study with regard to A. stolonifera focuses only on resources translocation between vegetative ramets and vegetative ramets with the same function. Studies on resources translocation between vegetative ramets and reproductive ramets with different functions are still lacking. Thus, it appears that it will be of great significance to carry out dynamic research on bidirectional translocation of resources between different functional ramets in the future.

A study regarding an ornamental plant Iris laevigata showed that vegetative ramets could translocate their resources to the connected reproductive ramets (Wang et al., 2017). Our study identified the allocation pattern and strategy of translocated resources between organs of reproductive ramets in $L$. chinensis. We found that the amount of translocated ${ }^{15} \mathrm{~N}$ was the largest in the stem, followed by the leaf, and it was the lowest in inflorescence (Table 3). Simultaneously, we also found that from the heading stage, all leaves of reproductive ramets gradually senesced (Figure 2), inflorescence biomass persistently increased, leaf biomass and stem biomass slightly decreased in late reproductive growth, but they remained statistically stable for a long time (leaf biomass remained stable between the 4 th and 7 th measurements, and stem biomass remained stable between the 2nd and 7th measurements) (Figure 4). All of these results suggest that with the senescence of leaves in physiological function, not only the stem but also the leaves (assimilating organs) require an external resource supply to maintain the metabolic consumption of life-sustaining activities and to maintain the physiological functions of leaves. This finding means that the amounts of translocated resources allocated to the vegetative organs (stem and leaf) for life-sustaining activities are much larger than those allocated to the reproductive organs 
TABLE 2 | Comparison of the $\delta^{15} \mathrm{~N}$ of reproductive ramets in Leymus chinensis between the control and ${ }^{15} \mathrm{~N}$ labeling treatments (means \pm SE, $n=4$ ).

\begin{tabular}{|c|c|c|c|c|c|}
\hline Variable & Year & CK & ${ }^{15} \mathrm{~N}$ labeling & $t$ & $P$ \\
\hline \multirow[t]{2}{*}{ Leaf $\delta^{15} \mathrm{~N}$} & 2017 & $1.45 \pm 0.53$ & $72.09 \pm 4.86$ & -14.44 & 0.001 \\
\hline & 2018 & $2.78 \pm 0.36$ & $138.06 \pm 16.16$ & -8.37 & 0.004 \\
\hline \multirow[t]{2}{*}{ Stem $\delta^{15} \mathrm{~N}$} & 2017 & $0.98 \pm 0.57$ & $90.46 \pm 10.59$ & -8.44 & 0.003 \\
\hline & 2018 & $2.45 \pm 0.32$ & $196.67 \pm 12.17$ & -15.95 & 0.001 \\
\hline \multirow[t]{2}{*}{ Inflorescence $\delta^{15} \mathrm{~N}$} & 2017 & $1.26 \pm 0.37$ & $23.37 \pm 1.80$ & -12.02 & $<0.001$ \\
\hline & 2018 & $1.88 \pm 0.17$ & $41.06 \pm 5.12$ & -7.66 & 0.005 \\
\hline
\end{tabular}

TABLE 3 | Mean translocated ${ }^{15} \mathrm{~N}$ mass allocation to various organs of reproductive ramets in Leymus chinensis over two consecutive years (means \pm SE, $n=4$ ).

\begin{tabular}{|c|c|c|c|c|}
\hline \multirow[t]{2}{*}{ Variable } & \multicolumn{2}{|c|}{2017} & \multicolumn{2}{|c|}{2018} \\
\hline & Mass $(\mu \mathrm{g})$ & Percentage (\%) & Mass $(\mu \mathrm{g})$ & Percentage (\%) \\
\hline Leaf ${ }^{15} \mathrm{~N}$ & $0.47 \pm 0.05 b$ & $14.35 \pm 1.79 b$ & $0.77 \pm 0.08 b$ & $14.08 \pm 1.57 b$ \\
\hline Stem ${ }^{15} \mathrm{~N}$ & $2.65 \pm 0.23 a$ & $79.19 \pm 2.16 \mathrm{a}$ & $4.34 \pm 0.17 \mathrm{a}$ & $78.85 \pm 1.14 \mathrm{a}$ \\
\hline Inflorescence ${ }^{15} \mathrm{~N}$ & $0.21 \pm 0.02 \mathrm{c}$ & $6.46 \pm 0.82 c$ & $0.39 \pm 0.03 c$ & $7.08 \pm 0.60 \mathrm{c}$ \\
\hline Total & $3.33 \pm 0.21$ & 100 & $5.50 \pm 0.15$ & 100 \\
\hline
\end{tabular}

Different lowercase letters for each year indicate significant differences $(P<0.05)$ between the organs.

(inflorescence) for forming seeds. Therefore, at least from the perspective of a short-term resource transfer, reproductive ramets adopt a strategy of growth first and reproduction later to allocate the translocated resources between organs.

\section{Role of Vegetative Ramets Connected to Tillering Nodes in Sexual Reproduction}

In clonal grass populations, it is often seen that a reproductive ramet has different numbers of connecting vegetative ramets on its tillering nodes. This is possibly because there are differences in size of reproductive ramets, capacity for vegetative propagation of tillering nodes of reproductive ramets, or environmental conditions (Xiao et al., 2011; Yuan et al., 2020). In this study, under a field homogeneous condition, we selected reproductive ramets of a similar size and with different numbers of connecting vegetative ramets at the edge of each plot where there was no competition between ramets, to carry out the experiment. Therefore, the difference in the number of connecting vegetative ramets involved in this study more likely result from the difference in capacity for vegetative propagation of tillering nodes of reproductive ramets and consequently the number of axillary buds produced.

In this study, at the early heading stage, we selected reproductive ramets of a similar size, with synchronous heading, and with different numbers of connecting vegetative ramets, as the experimental samples, thus reducing or eliminating the impacts of inherent difference and asynchronous heading on sexual reproduction performance ( $\mathrm{Li}$ et al., 2018). Additionally, the selected experimental samples were all located at the edge of each plot. Considering the small density of ramets at the edge, the large interval between ramets, and the proximity of resource supply, compared with vegetative ramets on the tillering nodes, other ramets had tiny effects on sexual reproduction performance. All ramets of $L$. chinensis in the experimental plots originally came from the same natural clone and were genetically identical, thereby excluding the effect of genetic differences on sexual reproduction performance. Therefore, we were pretty certain that vegetative ramets connected to tillering nodes had positive effects on the inflorescence biomass, floret number, seed number, seed-setting rate, seed biomass, reproductive allocation 1, and reproductive allocation 2 (Figures 5B1-H1, B2-H2), and these parameters were significantly and positively correlated with the biomass of the vegetative ramets (Figure 6). These results are against the second hypothesis. Most importantly, we showed that vegetative ramets are very advantageous for sexual reproduction under the tillerning node connection form in L. chinensis. Our study implies that vegetative ramets play an important role in the sexual reproduction apart from the spatial expansion of clonal plant populations.

Theoretically speaking, the more vegetative ramets connected to the reproductive ramet is, the better the sexual reproductive performance is. However, there are actually some deviations from this trend. We found that the inflorescence biomass and floret number were lowest when the reproductive ramet was connected to two vegetative ramets rather than one vegetative ramet (Figures 5B,C). Under natural conditions, individual sizes are irregular in most plant populations due to change in growth rates caused by factors such as genetic differences, spatial heterogeneity of resources or age differences (Weiner and Solbrig, 1984). Even in clonal populations of L. chinensis growing under a homogeneous condition, there were differences in age between the vegetative ramets connected to tillering nodes, leading to an irregularity in size. Therefore, the resource supply of the two connected vegetative ramets may be lower than that of the one connected vegetative ramet, and thus, sexual reproductive performance might also follow such a rule.

The degree to which vegetative ramets affect sexual reproductive performance varies with reproductive characteristics. We found that the number of vegetative 
ramets had no effect on inflorescence length but had significant effects on seed-related characteristics such as seed number, seed biomass, seed-setting rate, and reproductive allocation 2 (Figure 5), which may be due to the different formation times of each characteristic. On the Songnen Plain, L. chinensis usually enters the young spike differentiation stage soon after returning green on April 5, the inflorescence length begins to elongate from the early and medium stage of young spike differentiation and stops growing before the flowering stage (mid-June), and the seeds do not mature until mid to late July ( $\mathrm{Zhu}, 2004)$. Thus, it appears that the seed-related characteristics, because of their relatively long formation time, will receive resources from the connected vegetative ramets for a relatively long time and thus be strongly affected.

\section{CONCLUSION}

In clonal populations of L. chinensis growing under a field homogeneous condition, the photosynthetic contribution of the functional leaf to seed production was larger than that of the flag leaf; from the heading stage, all leaves of reproductive ramets gradually senesced. Vegetative ramets could translocate their own resources to the connected reproductive ramets through tillering nodes, and a larger proportion of these resources were allocated to vegetative organs to sustain life activities and less allocated to reproductive organs to form seeds. The number of vegetative ramets connected to tillering nodes positively affected sexual reproductive performance. However, the current study was conducted in a field homogeneous environment with only one level of resource supply. Further studies that explore effects of the flag leaf and the number of vegetative ramets connected to

\section{REFERENCES}

Anten, N. P. R., Hikosaka, K., and Hirose, T. (2000). "Nitrogen utilisation and the photosynthetic system," in Leaf Development and Canopy Growth, eds B. Marshall and J. A. Roberts (Sheffield: Sheffield Academic Press), 171-203.

Ao, H., Peng, S., Zou, Y., Tang, Q., and Visperas, R. M. (2010). Reduction of unproductive tillers did not increase the grain yield of irrigated rice. Field Crop. Res. 116, 108-115. doi: 10.1016/j.fcr.2009.11.020

Araus, J. L., and Tapia, L. (1987). Photosynthetic gas exchange characteristics of wheat flag leaf blades and sheaths during grain filling: the case of a spring crop grown under Mediterranean climate conditions. Plant Physiol. 85, 667-673. doi: $10.1104 /$ pp.85.3.667

Bai, Y., Han, X., Wu, J., Chen, Z., and Li, L. (2004). Ecosystem stability and compensatory effects in the Inner Mongolia grassland. Nature 431, 181-184. doi: 10.1038 /nature02850

Berry, G. J., Salisbury, P. A., and Halloran, G. M. (1980). Expression of vernalization genes in near-isogenic wheat lines: duration of vernalization period. Ann. Bot. 46, 235-241. doi: 10.1093/oxfordjournals.aob.a085912

Burnett, A. C. (2019). “Source-sink Relationships”, in eLS. Chichester: John Wiley \& Sons, Ltd.

Chang, T. G., and Zhu, X. G. (2017). Source-sink interaction: a century old concept under the light of modern molecular systems biology. J. Exp. Bot. 68, 4417-4431. doi: 10.1093/jxb/erx002

Chen, J. S., Zhu, R. F., and Zhang, Y. X. (2013). The effect of nitrogen addition on seed yield and yield components of Leymus chinensis in Songnen Plain. China. J. Soil Sci. Plant Nut. 13, 329-339. doi: 10.4067/S0718-95162013005000027 tillering nodes on sexual reproductive performance with different levels of resource supply will help us to better understand population adaptation and resource allocation of clonal grasses in future environments.

\section{DATA AVAILABILITY STATEMENT}

The datasets generated for this study are available on request to the corresponding author.

\section{AUTHOR CONTRIBUTIONS}

HL and YY designed the study. JG collected the data. JG, HL, CZ, and YY analyzed the data and wrote the manuscript. All authors read and approved the final manuscript.

\section{FUNDING}

This work was funded by the Natural Key Research and Development Program of China (2016YFC0500602), the National Natural Science Foundation of China (31672471, 31670427, 32071860, and 31570332), and the Program of Introducing Talents of Discipline to Universities (B16011).

\section{ACKNOWLEDGMENTS}

We want to thank Xuenan Hong and Yanqin Fan for help with field experiments. We would like to acknowledge the editor and reviewers for helpful comments on the manuscript.
Chen, S., Huang, X., Yan, X., Liang, Y., Wang, Y., Li, X., et al. (2013). Transcriptome analysis in sheepgrass Leymus chinensis: a dominant perennial grass of the Eurasian Steppe. PLoS One 8:e67974. doi: 10.1371/journal.pone.0067974

Cook, R. E. (1985). "Growth and development in clonal plant populations," in Population Biology and Evolution of Clonal Organisms, eds J. B. C. Jackson, L. W. Buss, and R. E. Cook (New Haven: Yale University Press), 259-296. doi: 10.2307/j.ctt2250w9n.11

Dhiman, S. D., Sharma, H. C., and Singh, R. P. (1980). Association between flag leaf area and grain yield in wheat. Plant Physiol. 23, 282-287. doi: 10.1016/01475975(80)90037-7

Duchoslavová, J., and Jansa, J. (2018). The direction of carbon and nitrogen fluxes between ramets changes during ontogeny under simulated competition for light. J. Exp. Bot. 69, 2149-2158. doi: 10.1093/jxb/ery068

Eckert, C. G. (2001). The loss of sex in clonal plants. Evol. Ecol. 15, 501-520. doi: 10.1023/A:1016005519651

Eriksson, O. (1989). Seedling dynamics and life histories in clonal plants. Oikos 55, 231-238. doi: 10.2307/3565427

Eriksson, O. (1992). Evolution of seed dispersal and recruitment in clonal plants. Oikos 63, 439-448. doi: 10.2307/3544970

Field, C. B., Behrenfeld, M. J., Randerson, J. T., and Falkowski, P. (1998). Primary production of the biosphere: integrating terrestrial and oceanic components. Science 281, 237-240. doi: 10.1126/science.281.5374.237

Gao, Y., Wang, D., Xing, F., Liu, J., and Wang, L. (2014). Combined effects of resource heterogeneity and simulated herbivory on plasticity of clonal integration in a rhizomatous perennial herb. Plant Biol. 16, 774-782. doi: 10. $1111 /$ plb. 12122 
Guo, J., Li, H., and Yang, Y. (2020). Phenotypic plasticity in sexual reproduction based on nutrients supplied from vegetative ramets in a Leymus chinensis population. Front. Plant Sci. 10:1681. doi: 10.3389/fpls.2019.01681

Harper, J. L. (1977). Population Biology of Plants. London: Academic Press.

Humbeck, K., Quast, S., and Krupinska, K. E. (1996). Functional and molecular changes in the photosynthetic apparatus during senescence of flag leaves from field-grown barley plants. Plant Cell Environ. 19, 337-344. doi: 10.1111/j.13653040.1996.tb00256.x

Jin, H., Kim, H. R., Plaha, P., Liu, S. K., Park, J. Y., Piao, Y. Z., et al. (2008). Expression profiling of the genes induced by $\mathrm{Na}_{2} \mathrm{CO}_{3}$ and $\mathrm{NaCl}$ stresses in leaves and roots of Leymus chinensis. Plant Sci. 175, 784-792. doi: 10.1016/j. plantsci.2008.07.016

Kuo, P. C. (1987). Flora Reipublicae Popularis Sinicae. Beijing: Science Press.

Li, H., Jin, X., and Yang, Y. (2018). Consequences of asynchronous heading in a perennial bunchgrass (Elymus excelsus). Sci. Rep. 8, 3323. doi: 10.1038/s41598018-21759-2

Li, J. D., Wu, B. H., and Sheng, L. X. (2001). Jilin Vegetation. Changchun: Jilin Science and Technology Press.

Li, Z. K., Pinson, S. R. M., Stansel, J. W., and Paterson, A. H. (1998). Genetic dissection of the source-sink relationship affecting fecundity and yield in rice (Oryza sativa L.). Mol. Breed. 4, 419-426. doi: 10.1023/A:10096081 28785

Lupton, F. G. H. (1972). Further experiments on photosynthesis and translocation in wheat. Ann. Appl. Biol. 71, 69-79. doi: 10.1111/j.1744-7348.1972.tb0 4717.x

Maynard Smith, J. (1971). "The origin and maintenance of sex," in Group Selection, ed. G. C. Williams (New York, NY: Aldine-Atherton Press), 163-175.

Nowicka, B., Ciura, J., Szymańska, R., and Kruk, J. (2018). Improving photosynthesis, plant productivity and abiotic stress tolerance-current trends and future perspectives. J. Plant Physiol. 231, 415-433. doi: 10.1016/j.jplph.2018. 10.022

Nuruzzaman, M., Yamamoto, Y., Nitta, Y., Yoshida, T., and Miyazaki, A. (2000). Varietal differences in tillering ability of fourteen japonica and indica rice varieties. Soil Sci. Plant Nutr. 46, 381-391. doi: 10.1080/00380768.2000. 10408792

Pan, R. Z. (2012). Plant Physiology. Beijing: Higher Education Press.

Pérez-Pérez, J. M., Esteve-Bruna, D., and Micol, J. L. (2010). QTL analysis of leaf architecture. J. Plant Res. 123, 15-23. doi: 10.1007/s10265-009-0267-z

Putz, B., Drapela, T., Wanek, W., Schmidt, O., Frank, T., and Zaller, J. G. (2011). A simple method for in situ-labelling with ${ }^{15} \mathrm{~N}$ and ${ }^{13} \mathrm{C}$ of grassland plant species by foliar brushing. Methods Ecol. Evol. 2, 326-332. doi: 10.1111/j.2041-210X. 2010.00072.x

Richards, A. J. (1986). Plant Breeding Systems. London: George Allen and Unwin Publishers.

Rousseaux, M. C., Hall, A. J., and Sánchez, R. A. (1996). Far-red enrichment and photosynthetically active radiation level influence leaf senescence in fieldgrown sunflower. Physiol. Plantarum 96, 217-224. doi: 10.1111/j.1399-3054. 1996.tb00205.x

Sedeek, S. E. M., Hammoud, S. A. A., Ammar, M. H., and Metwally, T. F. (2009). Genetic variability, heritability, genetic advance and cluster analysis for some physiological traits and grain yield and its components in rice (Oryza sativa L.). J. Agric. Res. Kafer El Sheikh Univ. 35, 858-878.

Smith, H. (2000). "Plant architecture and light signals," in Leaf Development and Canopy Growth, eds B. Marshall and J. A. Roberts (Sheffield: Sheffield Academic Press), 118-144.

Song, B., Yang, J., Xu, R., and $\mathrm{Wu}, \mathrm{J}$. (2003). Water use of Leymus chinensis community. Acta Bot. Sin. 45, 1245-1250. doi: 10.1023/A:1022289509702

Sugiura, N. (1978). Further analysis of the data by akaike's information criterion and the finite corrections. Commun. Stat Theor. Method 7, 13-26. doi: 10.1080/ 03610927808827599

Terashima, I., Araya, T., Miyazawa, S., Sone, K., and Yano, S. (2005). Construction and maintenance of the optimal photosynthetic systems of the leaf, herbaceous plant and tree: an eco-developmental treatise. Ann. Bot. 95, 507-519. doi: 10 . 1093/aob/mci049

Thorne, G. N., and Wood, D. W. (1987). The fate of carbon in dying tillers of winter wheat. J. Agr. Sci. 108, 515-522. doi: 10.1017/S0021859600079892

Walpole, P. R., and Morgan, D. G. (1972). Physiology of grain filling in barley. Nature 240, 416-417. doi: 10.1038/247297a0
Wang, L., Wang, H., He, C., Sheng, L., and Tang, Z. (2017). An irreversible division of labor through a sexually dependent system in the clonal plant Iris laevigata (Iridaceae). Ecosphere 8:e01757. doi: 10.1002/ecs2.1757

Wang, M. L. (1998). A study on seed production of Aneurolepidium chinensis. Grassl. China 20, 18-20. doi: 10.3321/j.issn:1673-5021.1998.01.005

Wang, R. (2000). Effect of grazing on reproduction in Leymus chinensis population. Chin. J. Appl. Ecol. 11, 399-402.

Wang, R. (2001). Photosynthesis, transpiration, and water use efficiency of vegetative and reproductive shoots of grassland species from northeastern China. Photosynthetica 39, 569-573. doi: 10.1023/A:10156602 13811

Wang, R., Gao, Q., and Chen, Q. (2003). Effects of climate on biomass and biomass allocation of Leymus chinensis (Poaceae) along the North-east China Transect (NECT). J. Arid Environ. 54, 653-665. doi: 10.1006/jare.2002.1087

Weaver, L. M., and Amasino, R. M. (2001). Senescence is induced in individually darkened Arabidopsis leaves, but inhibited in whole darkened plants. Plant Physiol. 127, 876-886. doi: 10.1104/pp.010312

Weiner, J., and Solbrig, O. T. (1984). The meaning and measurement of size hierarchies in plant populations. Oecologia 61, 334-336. doi: 10.1007/ BF00379630

Wingler, A., von Schaewen, A., Leegood, R. C., Lea, P. J., and Quick, W. P. (1998). Regulation of leaf senescence by cytokinin, sugars, and light: effects on NADH-dependent hydroxypyruvate reductase. Plant Physiol. 116, 329-335. doi: $10.1104 /$ pp.116.1.329

Woolhouse, H. W. (1987). "Leaf senescence," in The Biology of Plant Development, eds H. Smith and D. Grierson (Oxford: Blackwell Scientific Publications), 256-284.

Xiao, Y., Tang, J., Qing, H., Zhou, C., and An, S. (2011). Effects of salinity and clonal integration on growth and sexual reproduction of the invasive grass Spartina alterniflora. Flora 206, 736-741. doi: 10.1016/j.flora.2010. 12.003

Yang, W., Guo, Z., Huang, C., Wang, K., Jiang, N., Feng, H., et al. (2015). Genome-wide association study of rice (Oryza sativa L.) leaf traits with a high-throughput leaf scorer. J. Exp. Bot. 66, 5605-5615. doi: 10.1093/jxb/er v100

Yang, Y., Liu, G., and Zhang, B. (1995). An analysis of age structure and the strategy for asexual propagation of Aneurolepidium chinense population. Acta Bot. Sin. $37,147-153$.

Yang, Y., Yang, L., Zhang, B., and Li, J. (2000). Relationship between the fruitbearing characters of Leymus chinensis population and annual climatic variation in natural meadow in northeast China. Acta Bot. Sin. 42, 294-299.

Yin, L., Xu, H., Dong, S., Chu, J., Dai, X., and He, M. (2019). Optimised nitrogen allocation favours improvement in canopy photosynthetic nitrogenuse efficiency: evidence from late-sown winter wheat. Environ. Exp. Bot. 159, 75-86. doi: 10.1016/j.envexpbot.2018.12.013

Yin, X., and Kropff, M. J. (1996). Use of the Beta function to quantify effects of photoperiod on flowering and leaf number in rice. Agr. Forest Meteorol. 81, 217-228. doi: 10.1016/0168-1923(95)02324-0

Yoshida, S. (1972). Physiological aspect of grain yield. Ann. Rev. Plant Physiol. 23, 437-464. doi: 10.1146/annurev.pp.23.060172.002253

Yuan, J., Li, H., and Yang, Y. (2020). The compensatory tillering in the forage grass Hordeum brevisubulatum after simulated grazing of different severity. Front. Plant Sci. 11:792. doi: 10.3389/fpls.2020.00792

Yuan, S., Ma, L., Guo, C., and Wang, R. (2016). What drivers phenotypic divergence in Leymus chinensis (Poaceae) on large-scale gradient, climate or genetic differentiation? Sci. Rep. 6, 26288. doi: 10.1038/srep 26288

Yue, B., Xue, W., Luo, L., and Xing, Y. (2006). QTL analysis for flag leaf characteristics and their relationships with yield and yield traits in rice. Acta Genet. Sin. 33, 824-832. doi: 10.1016/S0379-4172(06) 60116-9

Zhang, C., Yang, C., and Dong, M. (2002). Clonal integration and its ecological significance in Hedysarum laeve, a rhizomatous shrub in $\mathrm{Mu}$ Us Sandland. J. Plant Res. 115, 113-118. doi: 10.1007/s1026502 00016

Zheng, Y., Wang, Z., Sun, X., Jia, A., Jiang, G., and Li, Z. (2008). Higher salinity tolerance cultivars of winter wheat relieved senescence at reproductive stage. Environ. Exp. Bot. 62, 129-138. doi: 10.1016/j.envexpbot.2007.07.011 
Zhou, C., Zhang, Z., Wang, Z., and Yang, Y. (2014). Difference in capacity of physiological integration between two ecotypes of Leymus chinensis underlies their different performance. Plant Soil 383, 191-202. doi: 10.1007/s11104-0142169-7

Zhou, Y., Gu, Z., Wang, A., Zhu, X., and Guo, W. (2007). Effects of removing unproductive tillers on grain yield and quality of wheat. Jiangsu Agr. Sci. 4, 18-20. doi: 10.3969/j.issn.1002-1302.2007. 04.007

Zhu, T. C. (2004). Biological and Ecological Study of Leymus Chinensis. Changchun: Jilin Science and Technology Press.
Conflict of Interest: The authors declare that the research was conducted in the absence of any commercial or financial relationships that could be construed as a potential conflict of interest.

Copyright (c) 2020 Guo, Li, Zhou and Yang. This is an open-access article distributed under the terms of the Creative Commons Attribution License (CC BY). The use, distribution or reproduction in other forums is permitted, provided the original author(s) and the copyright owner(s) are credited and that the original publication in this journal is cited, in accordance with accepted academic practice. No use, distribution or reproduction is permitted which does not comply with these terms. 